\title{
Design of Wireless Temperature and Humidity Acquisition and Alarm System for Calibration Laboratory
}

\author{
Ning Guo ${ }^{1, a}$, Kang Guo ${ }^{2, b}$, Xiangdong Mao ${ }^{1, c}$ and Haitao Liu ${ }^{1, d}$ \\ 1Shijiazhuang New Technology Application Institute, Shijiazhuang 050000, China; \\ ${ }^{2}$ Harbin Institute of Technology, Shenzhen 518055, China. \\ amhwl_gn_Imyy@163.com, bgkiambest@hotmail.com, cjxyjsbgb@126.com, d1151854667@qq.com
}

\begin{abstract}
Aiming at the high requirement of the environment of calibration lab, this paper designs a kind of wireless temperature and humidity acquisition and alarm system. This system based on AT89C52 microprocessor can collect, process and store the data from the sensor nodes in the laboratory and transmit the measurement data and alarm signal remotely through the SIM900A module. The sensor nodes are composed of AT89C2051, NRF2401 RF transceiver module, temperature and humidity sensor SHT11 and other components. The terminal control system can send an alarm signal and transmits it to the person in charge of the calibration laboratory with the temperature and humidity in the laboratory exceeds the threshold. The system can accurately monitor and record the temperature and humidity in the laboratory, and can send out the alarm signal when the data is overrun. So it can effectively avoid the experiment that verification, calibration and test under the unqualified condition, and it has very high practical value.
\end{abstract}

Keywords: wireless network; temperature and humidity sensor; alarming with overrun; SIM900A.

\section{Introduction}

Calibration has very high demands on the surrounding environmental factors, in particular the calibration of electronic equipment is very sensitive to temperature and humidity of the surrounding environment. To ensure the validity of measurement results and provide amendment, the environment must be controlled [1]. Currently, the laboratory temperature and humidity rely mainly on tester to observe and record thermo-hygrometer placed in the laboratories. This recording method is of low intelligence, and recording data is limited and is difficult to ensure continuous, which leading to the standard laboratory's temperature and humidity data cannot reasonably be aggregated and query time-consuming; If it encounters a standard calibration for a long time, and in some period of time without guard, temperature and humidity gauge cannot be known, making it difficult to guarantee the test data accurate and reliable. Since this method is restricted by time, environment and other factors, and a wired mode data communications system cannot fully meet all the conditions to the task, instead of wired data transmission via wireless data transmission, has become the main research direction to solve such problems [2]. Wireless sensor networks (WSNs) is a network information system with a set of distributed information gathering, information transmission and information processing technology, composed of a large number of wireless sensor nodes interconnection and composition in the form of wireless self-organization. Through the various types of sensors embedded in the node, it can detect and perceive all kinds of environmental objects in the network distributed area, and its work area with wide, poor, and complex [3-4].

In this paper, based on the calibration laboratory controlled temperature and humidity data requirements, and the characteristics of the nRF2401 and wireless network nodes, this paper adopts modular design method, design and build the laboratory temperature and humidity data acquisition and overrun warning system.

\section{Overall system structure}

Laboratory temperature and humidity acquisition and alarm system consists of information acquisition and processing subsystem and terminal control system. Information acquisition and 
processing subsystem is connected directly to the terminal control system via short-range wireless network. In order to obtain valid information of the temperature and humidity in the laboratory, this paper places the wireless sensor nodes measuring the indoor temperature and humidity in real time. Entire laboratory building has several standard Lab, each laboratory needs at least a wireless network node, and number them in a certain order. Wireless sensor nodes collect temperature and humidity information and compare with the set threshold, when the value is excessive, the node alarming, and the alarm information will be transmitted to the terminal control system, and send it through the GSM module as a text message to a specified phone, in order to take effective measures in time. Collected information is sent to the terminal control system in time-sharing scanning and saved to the memory chip, while displayed on the LCD real-time, for convenient viewing. Overall system structure is shown in figure 1.

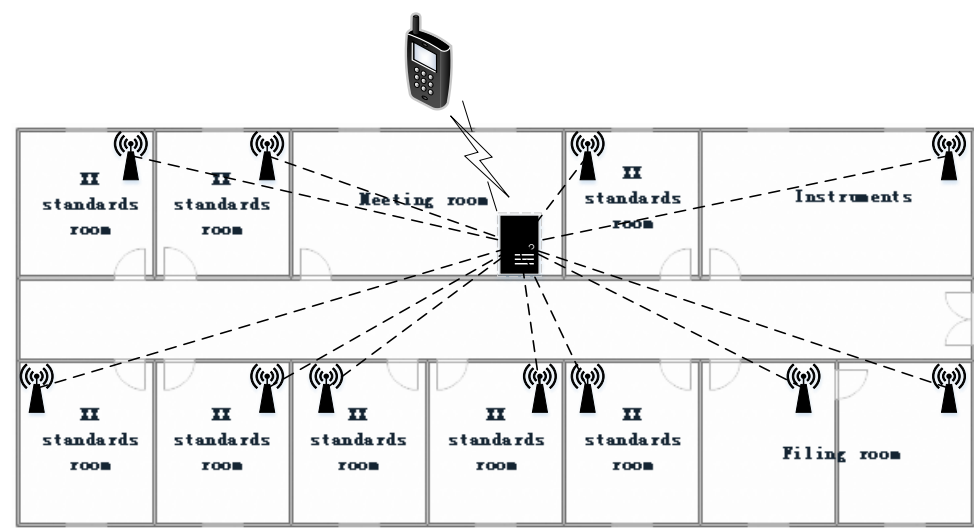

Fig. 1 Overall structure diagram of system

\section{Hardware design}

\subsection{Wireless Sensor Node Hardware Design}

Wireless sensor nodes are mainly composed of sensor module, processor module, wireless transceiver module, power supply module, etc. Wireless sensor nodes block diagram is shown in figure 2.

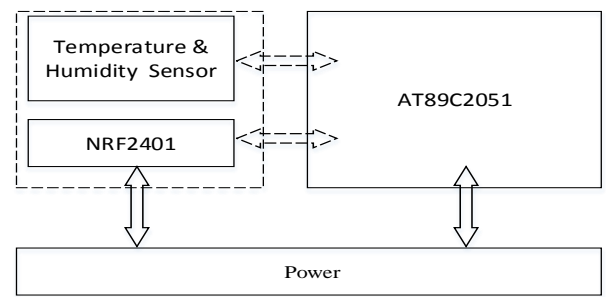

Fig. 2 Diagram of wireless sensor nodes

Microcontroller is AT89C2051 produced by US ATMEL Company with low-voltage, high-performance and COMS 8-bit, which is compatible with standard MCS-51 instruction set. Integrated on-chip are 8-bit general-purpose CPU, 2k bytes electrically erasable programmable read-only memory (EEPROM) and 128 bytes random access memory (RAM) [5]. The devices are manufactured with ATMEL's high density, nonvolatile memory technology. The device also features a 2-level program memory security lock, 15 programmable I / O lines, 6 Interrupt sources. The wireless communication chip NRF2401 works on global open $2.4 \mathrm{GHz}$ band with 125 channels, and can meet the needs of the multi-point frequency hopping. The transmission rate is $1 \mathrm{Mb} / \mathrm{s}$, and it also has high data throughput, which the transmission power and working frequency all working parameters can be designed through the software, such as voltage range of $1.9 \mathrm{~V}-3.6 \mathrm{~V}$ meeting the low power design requirements. It contains CRC error correction circuit and protocols, and supports point to multipoint communication address control, which can meet the design requirements of wireless network nodes. Temperature and humidity sensor using SHT11, and it contains a calibrated digital signal output temperature and humidity composite sensor produced by the Sensirion. The sensor is 
integrated with temperature sensor, humidity sensors, signal amplifier, AD converter, I2C bus interface and $\mathrm{CRC}$ generator. The power supply voltage range is $2.4 \mathrm{~V} \sim 5.5 \mathrm{~V}$, and the humidity measurement range is $0 \sim 100 \% \mathrm{RH}$, with a resolution of $0.3 \% \mathrm{RH}$. The temperature ranges from $-40{ }^{\circ} \mathrm{C}$ to $123.8{ }^{\circ} \mathrm{C}$, with a resolution of $0.01{ }^{\circ} \mathrm{C}$, which can meet the measurement range and accuracy. This paper designs two power supply modes for the power supply module, one is the battery-powered, suitable for wireless sensor node for free movement, the second is supplied by the city power through the power adapter, suitable for wireless sensor fixed in a region for a long time. And this paper prefer the second power supply mode based on the current situation of the laboratory.

\subsection{Hardware Design of Terminal Control System}

Terminal control system consists of central processing unit, storage unit, display unit, GSM module, wireless transceiver module and energy supply module. And the hardware block diagram of terminal control system is shown in Figure 3.

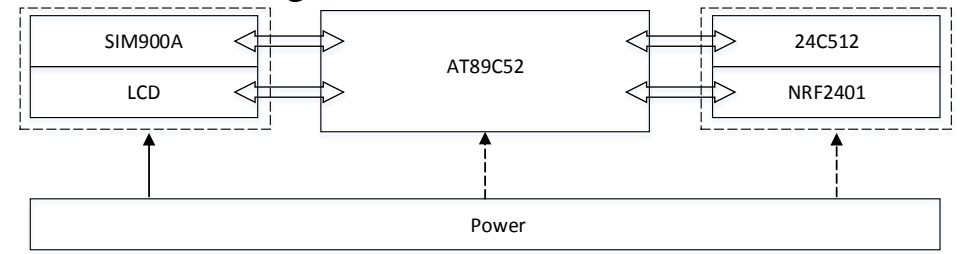

Fig. 3 Hardware block diagram of terminal control system

The central processing unit is AT89C52 produced by US ATMEL Company with low-voltage, high-performance and COMS 8-bit, which is compatible with standard MCS-51 instruction set. Integrated on-chip are 8k bytes flash memory and 256 bytes random access memory (RAM) [6]. There are 40 pins on the chip, and 32 external bidirectional I / O ports, with two external interrupts, three 16-bit timer counters, and two full-duplex serial communication ports. AT89C52 can be online programming, and combined with the rewritable flash memory can effectively improve the development efficiency and reduce development costs. In order to store the collected data for query at the same time, the terminal control system adopts $512 \mathrm{kB}$ serial electrically erasable programmable memory AT24C512 produced by ATMEL company to store the collected data and display it on LCD in real time. GSM module is SIM900A wireless module produced by SIMCom, and it is a dual-band GSM / GPRS module, fully encapsulated in SMT form and industry standard interface. And the operating frequency is $850 / 900 / 1800 / 1900 \mathrm{MHz}$. It also can support standard AT commands and enhanced AT commands [7]. With low power consumption to achieve voice, SMS, data and fax information transmission, it is the ideal solution for a variety of applications on high-speed data transmission.

\section{System software design}

\subsection{Construction of The Wireless Sensor Networks}

The wireless sensor network this paper builds includes the sensor node, the sink node and the task management node. Sensor nodes are arranged in the standard room, instrument library to collect room temperature and humidity data. These data are processed by the AT89C2051, and transmitted to the sink node via NRF2401. The sink node is placed in the middle room of the floor, and the collected data will be stored to the memory by the AT89C52 or transmitted to the computer storage through the serial port. And the overrun data will be transmitted by GSM module to the designated phone to achieve the alarm. The task management node can actively obtain temperature and humidity information of the sensor node in real time. Wireless sensor network architecture is shown in Figure 4. 


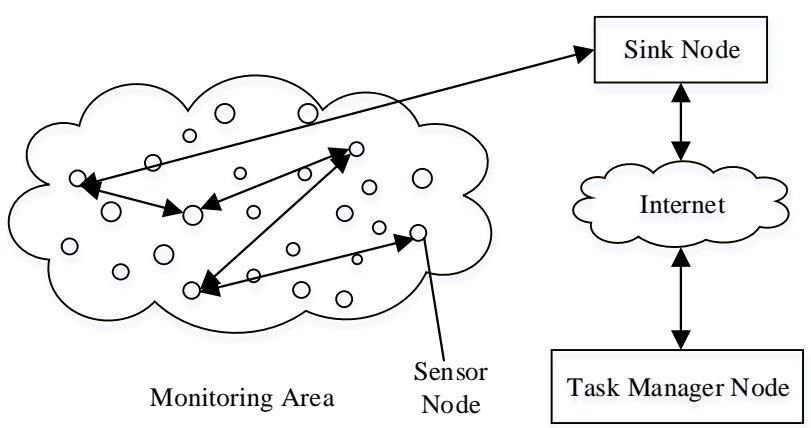

Fig. 4 Network architecture of wireless sensor

\subsection{Information Acquisition and Processing Subsystem Software Design}

The function of the information collecting and processing subsystem is that the temperature and humidity sensor collect the current temperature and humidity data and the MCU compares it with the threshold value, and extract and generate the alarm. Then, the data and the overrun alarm are sent to NRF 2401 by software simulation SPI of the MCU. And the system configures the NRF 2401 to the transmission mode to send data to the sink node. The workflow of this part is shown in Figure 5.

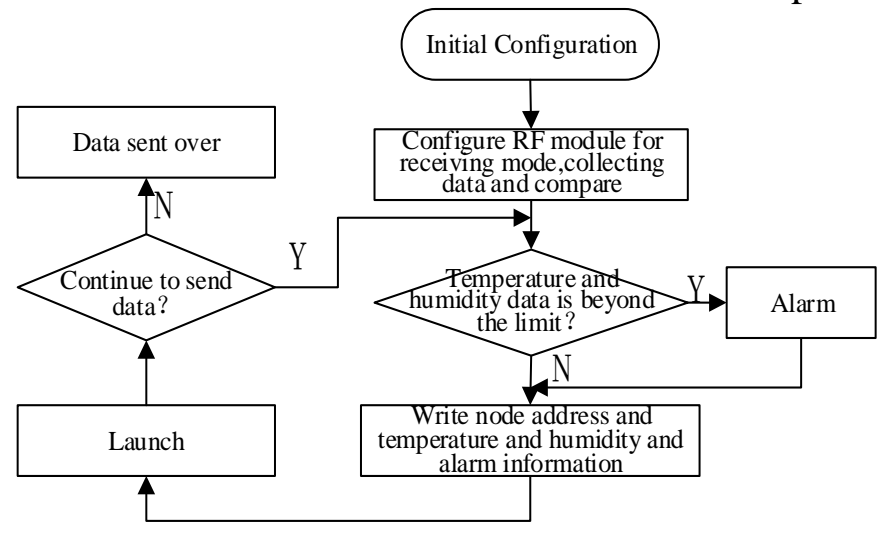

Fig. 5 The workflow chart of sensor node

Every node temperature and humidity threshold can be set by the system, and also by the mobile phone editing SMS by GSM - terminal control system - node controller, so that the design makes the threshold of each node change easily, and more versatile.

\subsection{Terminal Control System Software Design}

Terminal control system design function is that the microcontroller to receive and store the data and alarm information of each node through the receiver, and circularly display the standard room threshold and real-time detection value. When there is overrun alarm, the alarm module gives the alarm, and LCD display the alarming room and the overrun information will be sent to the mobile terminal through the GSM. The workflow of this part is shown in Figure 6.

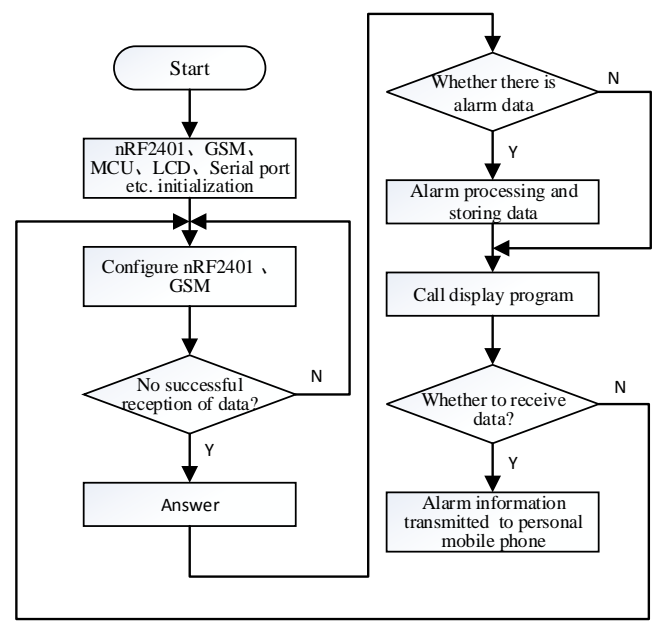

Fig. 6 Terminal control system workflow chart 
Terminal control system to store data is limited, so that the system can periodically transfer data to the computer through the serial port connected to the computer; and the terminal control system alarm can be closed through the phone to send the command message.

\section{Experimental results}

This paper randomly selects six standard labs to arrange the wireless sensor node and the calibrated thermo-hygrometer to monitor the indoor temperature and humidity, and arranges the terminal control system in the conference room to store and display the collected data and early warning for the overrun. Use of air conditioning and humidifier to regulate the indoor temperature and humidity for a period of time, and then record the temperature and humidity and the value of terminal control system displayed on the LCD. The data is shown in table 1.

Table 1 Test results of laboratory temperature and humidity

\begin{tabular}{cccccccccc}
\hline $\begin{array}{c}\text { Serial } \\
\text { numb } \\
\mathrm{er}\end{array}$ & $\begin{array}{c}\text { Humidity } \\
\text { of } \\
\text { calibratio } \\
\text { n room } \\
(\% \mathrm{RH})\end{array}$ & $\begin{array}{c}\text { Humidity } \\
\text { measureme } \\
\text { nt system } \\
(\% \mathrm{RH})\end{array}$ & $\begin{array}{c}\text { Humidi } \\
\text { tyof } \\
\text { humidit } \\
\text { y meter } \\
(\% \mathrm{RH})\end{array}$ & $\begin{array}{c}\text { Deviati } \\
\text { on } \\
(\% \mathrm{RH})\end{array}$ & $\begin{array}{c}\text { Temperat } \\
\text { ure of } \\
\text { calibratio } \\
\text { n room } \\
\left({ }^{\circ} \mathrm{C}\right)\end{array}$ & $\begin{array}{c}\text { Temperatu } \\
\text { re } \\
\text { measureme } \\
\text { nt system } \\
\left({ }^{\circ} \mathrm{C}\right)\end{array}$ & $\begin{array}{c}\text { Temperat } \\
\text { ure of } \\
\text { humidity } \\
\text { meter } \\
\left({ }^{\circ} \mathrm{C}\right)\end{array}$ & $\begin{array}{c}\text { Deviati } \\
\text { on }\end{array}$ & $\begin{array}{c}\text { Mobilepho } \\
\text { ne display }\end{array}$ \\
\hline 1 & $45 \sim 65$ & 75.6 & 75.9 & -0.3 & $19 \sim 21$ & 20.1 & 20.3 & -0.2 & $\begin{array}{c}\text { Humidity } \\
\text { alarm }\end{array}$ \\
2 & $20 \sim 80$ & 42.5 & 42.4 & 0.1 & $15 \sim 25$ & 19.6 & 19.1 & 0.5 & Normal \\
3 & $\leq 90$ & 45.6 & 44.9 & 0.7 & $5 \sim 35$ & 22.3 & 22.4 & -0.1 & Normal \\
4 & $\leq 80$ & 37.3 & 37.8 & -0.5 & $18 \sim 28$ & 25.5 & 25.8 & -0.2 & Normal \\
5 & $\leq 80$ & 45.7 & 45.8 & -0.1 & $15 \sim 21$ & 21.6 & 21.4 & 0.2 & $\begin{array}{c}\text { Temperatu } \\
\text { re display }\end{array}$ \\
\hline
\end{tabular}

From Table 1, it can be concluded that the wireless sensor nodes are consistent with the calibration of thermo-hygrometer values, and the maximum temperature difference is $0.5{ }^{\circ} \mathrm{C}$ and the maximum humidity difference is $0.7 \% \mathrm{RH}$, so that the error range is small, which can meet the requirements of laboratory. Among them, the standard room 1 verification regulation requires the temperature between $19{ }^{\circ} \mathrm{C}$ to $21{ }^{\circ} \mathrm{C}$, and the relative humidity in $40 \%$ to $60 \%$. And the standard room 6 verification regulation requires the temperature in $15{ }^{\circ} \mathrm{C}$ to $21{ }^{\circ} \mathrm{C}$, and the relative humidity $\leq 60 \%$. From the monitoring results, we can see that the humidity and temperature of the two standard labs exceed the error limit respectively. The system has audible and visual alarm, and the LCD has beyond the error limit display. At the same time, the mobile phone receives the information.

\section{Conclusion}

The experimental results show that the design of the system is simple and reliable; the software design is reasonable and efficient; the speed of data transmission is high; the system is stable with accurately collecting data, excellent in real-time and easy to expand and install, which can meet the laboratory temperature and humidity monitoring, data acquisition and overrun alarm requirements.

\section{References}

[1] General requirements for the testing and calibration laboratory capability ISO/IEC17025:2005.

[2] Zhu Rongtao, Ye Chuantao. Design of wireless temperature and humidity detection system based on nRF2401 and STC15F2K61S2 [J]. Petroleum Equipment, 2014, 28 (1): 29-31 \& 34.

[3] Wang Shu, Yan Yujie, Hu Fuping, etc. Wireless sensor network theory and application [M]. Beijing. Beijing University of Aeronautics and Astronautics Press, 2007.

[4] Sun Limin, Li Jianzhong, Chen Yu, et al. Wireless Sensor Networks [M]. Beijing: Tsinghua University Press, 2005: 391-402.

[5] AT89C2051 Datasheets.

[6] AT89C52 Datasheets.

[7] AT Command Set for TC35i [J]. Siemens Mobile Company, 2003. 